\title{
Discussion: Study of aeration efficiency at stepped channels
}

\section{A. Baylar and M. E. Emiroglu}

P. Novak, University of Newcastle uponTyne, UK

(a) As shown by Figs 4-6 the experiments covered both the nappe and skimming flow regimes and thus necessarily also the transition between the two types of flow. As the aeration mechanism for flow on cascades varies substantially between the three flow regimes it would have been useful to tie in the discussion of the aeration efficiency more closely with the flow regime.

(b) The authors discuss in some detail the length of the non-aerated flow region. If the total height of the cascade (i.e. total drop) is about $1.25 \mathrm{~m}$ (the authors only state the height of the approach channel above the laboratory floor) this gives a length of the cascade between 3.00 and $4.80 \mathrm{~m}$ for the tested slopes. With the length of the non-aerated region between 0.5 and $2.00 \mathrm{~m}$ (Figs 3 and 4) very substantial parts of the cascade in the authors' experiments did not contribute to the aeration process, which must influence the total aeration efficiency and thus makes the more general application of the results questionable.

(c) By working with cascades with a constant total fall the authors have excluded an important design variable and thus their equation (5) can be considered as representing only a case study.

(d) The authors claim that their literature search did not identify any published analytical or physical studies of dissolved oxygen levels produced in stepped channels. It is a matter of regret that they are unaware of the work by Essery, Tebbut and Rasaratnam who researched the re-aeration of stepped cascades and published detailed design graphs in $1977^{31}$ and $1978 .^{32}$ These results covered a range of slopes from 1:5 to $1: 1$ with an overall fall between 1 and $2 \mathrm{~m}$ and step heights 50 to $500 \mathrm{~mm}$. Direct comparison with the authors' equation (5) is not easy without further information as the design graphs include the number of steps and thus the height of the cascade (results with a total fall of $0.5 \mathrm{~m}$ or less were excluded). However a rough computation for a step height $0.1 \mathrm{~m}$, slope $1: 2.5$ and $y_{\mathrm{c}} / l=0.5$ giving $q=140 \times 10^{-3} \mathrm{~m}^{2} / \mathrm{s}$ (all within the authors' range of data) and assuming 12 steps gives an $r_{20}$ value of 1.48 for the Essery et al. results and 1.30 for equation (5). The difference may be due to the fact that for the authors' equation a substantial part of the assumed 12 steps was not effective because of the initial non-aerated part of the cascade and a better comparison with better results may be obtained by reducing the number of steps in the Essery et al. procedure.

(e) Avery and Novak in their 1978 paper (see authors' reference 3) drew attention to a cascade consisting of a series of pools which under certain circumstances gives similar or better results of oxygen uptake as a single step with a plunging jet. Novak $^{33}$ also compared a cascade as investigated by Essery et al. with a cascade of pools and a single jet/pool configuration.

\section{Authors'reply}

Point $(a)$. The discusser is right. The paper covered the nappe and skimming flow regimes. The transition flow regime was not considered in the study. The transition flow regime will be taken into account in the future studies.

Points $(b)$ to $(c)$. In this paper, the total height of the stepped channel was taken as $1.25 \mathrm{~m}$. The main purpose of this study was to investigate the effect of chute inclination angle, step height, flow discharge and flow regime upon the aeration efficiency of the stepped channel.

Point (d). Equation (5) is valid for $14.48^{\circ} \leq \alpha \leq 22 \cdot 55^{\circ}$. There is an erratum in equation (5). On page 262 in equation (5), the constant, $0 \cdot 262$, should be $0 \cdot 549$; therefore the corrected equation should be in the following form:

\begin{tabular}{|l|l|}
\hline 5 & $E_{20}=1-\left[1+2 \cdot 161(\sin \alpha)^{0.290} 0 \cdot 549^{\left(y_{\mathrm{c}} / h\right)}\right]^{-1}$ \\
\hline
\end{tabular}

A rough computation for a step height $0.1 \mathrm{~m}$, slope $1: 2.5$ and $y_{\mathrm{c}} / l=0.5$ giving $q=140 \times 10^{-3} \mathrm{~m}^{2} / \mathrm{s}$, which gives $r_{20}=1.77$ for equation (5).

Point (e). In this paper, the aeration efficiency of the stepped channels with end sill was not investigated.

\section{REFERENCES}

31. Tebbutt T. H. Y., Essery I. T. S. and Rasaratnam S. K. Reaeration performance of stepped cascades. Journal of the Institution of Water Engineers and Scientists, 1997, 31, No. 4, 285-296. 
32. Essery I. T. S., Tebbutt T. H. Y. and Rasaratnam S. K. Design of spillways for Re-aeration of Polluted Waters. Construction Industry Research and Information Association, London, 1978, Report No. 72.
33. NovaK P. Improvement of water quality in rivers by aeration at hydraulic structure. In Water Quality and its Control (Hino M. (ed.)). International Association of Hydraulic Research, Madrid, 1994.

\section{What do you think?}

To comment on this paper, please email up to 500 words to the editor at journals@ice.org.uk

Proceedings journals rely entirely on contributions sent in by civil engineers and related professionals, academics and students. Papers should be 2000-5000 words long, with adequate illustrations and references. Please visit www.thomastelford.com/journals for author guidelines and further details. 